\title{
A inversio no Cancioneiro geral de Garcia de Resende: adynata e sínquises
}

\author{
The inversio in Garcia de Resende's Cancioneiro \\ geral: adynata and synchysi
}

Geraldo Aucusto Fernandes*

Resumo: Os adynata e os versus rapportati são recursos embelezadores extremos que os poetas clássicos usavam para expressar as inversões - tanto aquelas de um mundo em mutação, quanto aquelas de preciosismo na expressão poética. É a esses recursos que recorrem os poetas do Cancioneiro geral de Garcia de Resende de 1516. Este estudo pretende mostrar exemplos de sínquise e de adynaton do Cancioneiro, e analisar se esses tropos foram possivelmente usados pelos poetas do Cancioneiro como artifício de linguagem poética ou de expressão de pensamento: seriam apenas artifício poético ou expressão de um mundo invertido, transgredindo todo um conceito de estabilidade e de segurança?

Palavras-chave: Cancioneiro geral de Garcia de Resende, adynata, sínquise, retórica, tropos

\begin{abstract}
The adynata and the versus rapportati are extreme embellishing means that the classical poets used to express the inversions -those of a world in mutation as well as those of preciosity for the poetical expression. In order to express poetically the poets of the Garcia de Resende's Cancioneiro geral of 1516 take advantage of these resources. This study intends to show examples of the synchysis and of the adynata and analyze if the tropes were possibly used by the poets of the Cancioneiro as a skill of poetical language or of expression of the thought: would those tropes be only a poetical mean or expression of a world inverted, transgressing the concepts of stability and security?
\end{abstract} Keywords: Garcia de Resende's Cancioneiro geral, adynata, synchysis, rhetoric, tropes

\footnotetext{
* Professor de Literatura Portuguesa na Universidade Federal do Ceará.
} 
o Livro IV da Retórica a Herênio, o autor divide as figuras de retórica em dois grupos, as de diç̧ão, ${ }^{1}$ sendo os tropos uma subclasse, e as figuras de pensamento. Em sua Institutio oratoria, no Livro IX, Quintiliano concilia as teorias de Aristóteles e do pseudo-Cícero, distinguindo "figuras" de "tropos". Para Quintiliano, as figuras estariam ligadas à forma, especificamente, à linguagem, em que, diferentemente dos tropos, não há alteração de ordem ou de sentido das palavras. ${ }^{2}$ Nos tropos, partindo do conceito de metáfora definido por Aristóteles, no Capítulo XXI de sua Poética, as palavras adquirem sentido distinto de sua expressão original, denotativa. ${ }^{3}$ Ambos, no entanto, partilham do mesmo objetivo que é dar ornamento à elocução discursiva. Tendo em vista esta classificação, parece-me necessário estudar de quais artifícios retóricos se valeram os poetas palacianos portugueses, seguindo esses mesmos conceitos, uma vez que tanto Cícero como Quintiliano foram venerados na Idade Média. Tendo em vista serem

1 No seu A commentary on Aristotle's Poetics, O. B. Hardison diz que Aristóteles "treats diction as an active concept and relates it closely to the poet's command of the meters. It is not 'metrical composition' but 'the act... of making metrical compositions' (I.13). This narrow definition is later expanded (Chapters XX-XXII) to include not only metrical composition but also word usage and imagery" [trata a dicção com um conceito ativo e o relaciona ao comando que o poeta tem da métrica. Não é uma "composição métrica" mas "o ato de criar composições métricas" (1.13). Esta definição estreita é logo expandida (Capítulos XX-XXII) para incluir não somente a composição métrica, mas também o uso das palavras e imagens] (ARISTÓTELES, 1981, p. 121). O conceito de diç̧ão expande-se, então, de arte de compor os metros para um processo de se produzir um texto literário (ibidem, p. 121). Ao comentar o conceito de Aristóteles sobre "dicção", escreve Hardison: "Aristotle feels that the special characteristic of poetic diction is its elevation and that it is obviously impossible to produce something more elevated than ordinary speech by using the language and techniques of ordinary speech" [Aristóteles sente que a característica mais particular da dicção poética é sua elevação e que é obviamente impossível produzir algo mais elevado do que a fala ordinária usando somente a linguagem e as técnicas da fala comum] (ibidem, p. 258).

2 Para as figuras, usa Edmond Faral o termo "ornement facile", i.e., o ornatus facilis das poéticas medievais, e consiste "d'une part, dans l'emploi des 'couleurs de rhétorique' (figures de mots et de pensée) ; d'autre part, dans un certain usage de la 'determination'", que Vinsauf e Garlande consideravam um "nouveau procédé" - é uma operação em que se junta a um nome um verbo, adjetivo ou um outro nome que serve de complemento; é ainda quando se junta ao adjetivo ou ao verbo um dos complementos próprios a eles. Diz que se considerava ornamento somente quando há acumulação (FARAL, 1982, p. 91, 97).

3 Edmond Faral escreve que o ornatus difficilis se caracteriza pelo uso dos tropos, cujo princípio é empregar palavras num sentido diferente de sua própria significação (do denotativo para o conotativo). Matthieu de Vendôme enumera a metáfora, a antítese, a metonímia, a sinédoque, a perífrase, a alegoria e suas variações e o enigma, como tropos. Observe-se que, diferentemente de Quintiliano e outros teóricos, a antítese para Vendôme é tropo e não figura (ibidem, p. 89). 
muitos os poemas reunidos no Cancioneiro geral de Garcia de Resende, corre-se o risco de tornar-se o levantamento muito esquemático, levando assim ao fastio, o que procurarei não o fazer. Sendo assim, creio que poucos exemplos serão representativos; esses exemplos serão tirados apenas dos poemas de formas mistas $^{4}$ e valem como referência para toda a coletânea de Resende.

\section{Os poetas palacianos e suas "alterações artísticas": os tropos}

Heinrich Lausberg relata que "ao docere informativo correspondem, como fenómenos de estranhamento, o genus obscurum e os tropos e figuras que procuram a obscuritas" (LAUSBERG, 1966, p. 113). Os tropos seriam uma forma de obscuritas quanto à direção; servem ao ornatus e ao estranhamento e são o mais alto grau da perspicuitas (ibidem, p. 128). Diz, ainda, que "a primaridade [quando tropos são empregados pela primeira vez] pode corresponder a uma opinião (errada) do sujeito falante, ou a uma opinião (errada) do ouvinte, enquanto, na realidade histórica, esse tropo, empregado pelo sujeito falante, já é, há muito, usual" (ibidem, p. 143-144). Os tropos seriam, então, uma forma mais engenhosa de demonstrar agudeza e sutileza, pois demandam não só perspicácia do emissor como também do destinatário. Quintiliano, no Livro VIII, escreve que "a trope is meant the artistic alteration of a word or phrase from its proper meaning to another" (QUINTILIANO, VIII, VI, I). Desprezando as discussões sobre os gêneros e espécies levadas a cabo por autores e por filósofos, o retor romano propõe-se a discutir os tropos mais necessários e mais aceitos, contentando-se com o fato de que alguns são empregados para ajudar no que se pretende significar, e outros servem para adornar o estilo; alguns são usados denotativamente, outros metaforicamente; e, ainda, que as alterações concernem não só a palavras isoladas, mas também a pensamentos e a estrutura das sentenças (ibidem, VIII, VI, 1-3).

No Livro IX, antes de discutir sobre as figuras, Quintiliano reforça a questão de que figuras e tropos estão em estreita relação, pois muitos autores - e ele

\footnotetext{
4 A característica básica desses poemas é ser iniciado por uma forma que se distingue das outras na sequência - por exemplo, inicia-se uma composição por cantiga, e depois há trovas e/ou um ou mais vilancetes. Esse modo de composição é original e foi uma das grandes inovações dos poetas de 1400 e 1500, castelhanos ou portugueses.
} 
mesmo - consideram aquelas idênticas a estes. Quanto ao emprego, ambos servem ao mesmo propósito: "they add force and charm to our matter" (ibidem, IX, I, 1-2). No entanto, mesmo que tão próximos em sentido e aplicação, crê ser necessário distinguir os dois processos - o que o faz num extenso parágrafo, do qual reproduzo uma das partes mais importantes:

The name of trope is applied to the transference of expressions from their natural and principal signification to another, with a view to the embellishment of style or, as the majority of grammarians define it, the transference of words and phrases from the place which is strictly theirs to another to which they do not properly belong. A figure, on the other hand, as is clear from the name itself, is the term employed when we give our language a conformation other than the obvious and ordinary. (ibidem, IX, , 4)

[O termo tropo é aplicado à transferência da expressão, de seu significado natural e principal para um outro significado, com o propósito de ornamentar o estilo ou, conforme é definido pela maioria dos gramáticos, a transferência de palavras e frases do lugar que estritamente the corresponde para um outro que não é o seu. Por outro lado, uma figura, como seu nome já indica, é o termo empregado quando Ihe damos em nossa língua uma conformação diferente da obvia e ordinária]

Elenca em seguida os tropos que se caracterizam pela substituição de uma palavra para outra, como a metáfora, a metonímia, a metalepse, a sinédoque, a catacrese, a alegoria e a hipérbole. Inclui entre os tropos a onomatopeia porque é a criação de uma palavra e, por isso mesmo, envolve substituição de palavra. Quanto à perífrase, diz que se caracteriza pelo uso de várias palavras no lugar de uma só. Inclui também a antonomásia e o hipérbato, que muitos não o consideram tropo, uma vez que é a mudança da ordem frasal, contudo, é uma transferência de uma palavra ou parte de palavra, daí dever ser considerada um tropo, pois uma figura não envolve necessariamente qualquer alteração de ordem ou de sentido estrito. Quanto à ironia, considera ser ora figura ora tropo, e admite ser complicada tal consideração devido às muitas discussões sobre a matéria entre os autores (ibidem, IX, I, 5-7). Sobre isso e sobre as distinções gerais entre os dois fenômenos, finaliza dizendo que 
it makes no difference by which name either is called, so long as its stylistic value is apparent, since the meaning of things is not altered by a change of name. For just as men remain the same, even though they adopt a new name, so these artifices will produce exactly the same effect, whether they are styled tropes or figures, since their values lie not in their names, but in their effect. Similarly it makes no difference whether we call a basis conjectural or negative, or concerned with fact or substance, provided always that we know that the subject of enquiry is the same. It is best therefore in dealing with these topics to adopt the generally accepted terms and to understand the actual thing, by whatever name it is called. But we must note the fact that trope and figure are often combined in the expression of the same thought, since figures are introduced just as much by the metaphorical as by the literal use of words. (ibidem, IX, I, 7-9).

[não faz diferença qual termo é empregado sempre que seu valor estilístico seja aparente porque o significado das coisas não é alterado pela mudança de sua denominação. Da mesma maneira que os homens permanecem os mesmos, ainda quando adotam um outro nome, estes artifícios produziram o mesmo efeito, ainda que chamados de tropos ou figuras porque seu valor não reside no nome, mas no seu efeito. Também não faz diferença chamar uma base de conjectural ou negativa, ou relacionada com facto ou substância, sempre que saibamos que o assunto analisado é o mesmo. O melhor ao tratar destes temas é adotar os termos geralmente aceitos e compreender o objeto real, independente do nome pelo que é denominado. Mas devemos notar o fato que tropo e figura são frequentemente combinados na expressão de um mesmo pensamento, porque as figuras são introduzidas tanto pelo uso metafórico como literal das palavras].

Para embelezar o estilo ou para adequar a elocução ao ritmo e à rima, os poetas palacianos portugueses serviram-se de variadas figuras e tropos. Um destes é a inversio, ${ }^{5}$ ou seja, a inversão de palavras ou de frases. Lausberg comenta que

\footnotetext{
$5 \mathrm{Na}$ arte oratória, há uma coincidência quanto à questão do "descortino de ideias" que tanto a figura quanto o recurso do orador podem provocar na elocução. Massaud Moisés explica que, no caso da arte oratória, "o descortino das ideias que haveriam de nortear o discurso se articulava estritamente ao modo como se disporiam ou se estruturavam. Ou seja, o orador procurava não só a melhor doutrina como a forma adequada de expressão, de modo a processar-se identidade perfeita entre a invenção e as partes dos discursos..." (MOISÉS, 2004, p. 243-244). Na oratória,
} 
a anástrofe, inversão, é a mudança de posição de membros da frase, contrária à consuetudo (LAUSBERG, 1966, p. 202-203). Esse artifício é exemplificado por Baltasar Gracián com aquilo que ele denomina "epigrama retrógrado": "especie de enigmas que hablan a dos luces, y se há de entender en ellos todo lo contrario de lo que dicen" (GRACIÁN, 1988, II, p. 166). Comenta também que

aunque es agudeza material, se estima por su picante malicia. Fue celebrado este epigrama, que leído al revés, y comenzando por la última palabra, dice todo lo contrario de lo que parece, pero no de lo que pretende:

Lares tua, non tua fraus, virtus, non copia rerum

Scandere te fecit hoc decus eximium.

Condito tua sit stabilis, nec tempore parvo.

Vivere te faciat hic Deus Omnipotens ${ }^{6}$.

Entre os efeitos para ornar o discurso, Quintiliano cita "the elegant inversion of words" (QUINTILIANO, IX, I, 34); quanto à expressão inversio, Quintiliano lembra que é o nome latino para "alegoria", em que uma das possíveis inversões estaria na absoluta oposição do significado das palavras (ibidem, VIII, VI, 44). No Cancioneiro geral, destacam-se as inversões de palavras (a anástrofe ${ }^{7}$ propriamente dita) ou de frases, no hipérbato, nos parênteses, no adynaton e na sínquise; destes dois últimos me ocuparei neste estudo.

As inversões aparecem em muitos poemas do $C G G R,{ }^{8}$ como anástrofes e hipérbatos, pelo que se pode constatar em alguns poucos exemplos que seguem:

Portugues ou castelhano / vós venhaes muito embora, / sei que vindes mui ufano / por ũu anno / qu'andastes de Moura fora. (CGGC, I, 92)

então, a questão se relaciona à organização do discurso, quando na poética a relação é estética.

6 Possível tradução: “Os Lares teus não teu agravo; tua virtude, não tua fortuna / Esta glória exímia fez te elevares. / O tempo, que te seja constante, não breve instante determinado./ Aqui te faça viver Deus Onipotente" (AGNOLON, Alexandre. Epigrama retrógrado, tradução comentada. Mensagem eletrônica recebida por <geraldoaugust@uol.com.br>, em 18. out. 2005).

7 "When, however, the transposition is confined to two words only, it is called anastrophe, that is, a reversal of order. This occurs in everyday speech in mecum and secum..." (QUINTILIANO, IX, VI, 65).

8 A sigla CGGR será usada para se referir ao Cancioneiro geral de Garcia de Resende. 
A ti que poder en mi / tienes por tu gran beldad, / que temo desque te vi / no pierda la libertad. (CGGC, I, 139).

Mazcarenhas Lianor / que tanto senhora minha / soia ser / diraa: - Sento grande dor, / morrerdes-me tam asinha / sem vos ver! (CGGC, II, 216). Observe-se que a primeira inversão (a de nome próprio) o poeta a fez para rimar.

Servir-vos nam leixaria / por mal que me ja viesse, / porque ser nam poderia / que outrem prazer me desse. (CGGC, II, 226).

Vos de mi no dar loores, / mas recebirlos deveis, / vos, gran senhor de senhores, / que haveis fecho y fazeis / tanto que grandes autores / muy acupados teneis / en dezir vuestros dulçores, / porque siempre vos Ihameis / princepe de los mejores, / porque creçan los lavores / desse reino portugues. (CGGC, II 256).

Ni más procure deseo / dar a mis males salida, / que de vida yo posseyo / consuelo de mi, que veyo / que la mejor escogida / possession que da ventura, / quando se buelv'al revés / su deleite y su dulçura, / que fue, ni será, ni es / cuidado es pera despues. (CGGC, II, 282).

Pera servir e adorar / fui eu nacido, / e vós soo para passar / o que nam pod'alcançar/ nenhũ humano sentido. (CGGC, III, 569)

O adynaton ou impossibilia é um dos tropos em que a inversão se dá no nível do pensamento. Muito usado pelos poetas palacianos, o adynaton quinhentista tem um objetivo bem fundado: os poetas, ante um mundo em mutação, principalmente pelas Conquistas e os males que estas trazem à antiga vida idealizada de moralidade e de simplicidade, sentem estar o mundo virado ao contrário. No entanto, o recurso é usado também nos poemas satíricos e amorosos; Giuseppe Tavani escreve que "a cultura cómica tem isto de peculiar: não inventa, não cria, mas modifica, altera, inverte. Veja-se, por exemplo, o caso do motivo do 'mundo às avessas'" (TAVANI, 1984, p. 68). Segundo Tavani, a origem dos adynata estaria em Arquíloco e que os de Virgílio eram muito conhecidos na Idade Média quando esse mundo da impossibilia passaria a fazer parte de patrimônio cultural - aparece em Teodulfo de Orléans e Valafrido Estrabão, nos Carmina 
Burana, em Alan de Lille, Chrétien de Troyes, Arnault Daniel e outros, até o século XVIII; na poesia galego-portuguesa aparece "sob duas facetas contraditórias: a do lamento tradicional [...] e a da representação, pura e simples, do mundo subvertido como de um mundo normal" (ibidem, 1984, p. 69-70). Na "cultura carnavalesca" medieval, isto é, quando os papéis sociais se invertem no curto período do carnaval, diz Mikhail Bakhtin que "a segunda vida, o segundo mundo da cultura popular, constrói-se de certa forma como paródia da vida ordinária, como um 'mundo ao revés'” (BAKHTIN, 1999, p. 10); nessa cultura, então, o que prevalece é um mundo em que não há racionalidade, vige a sátira, um jocoso modo de viver. De acordo com o Dicionário de termos literários, esta figura de linguagem é uma hipérbole que traduz impossibilidade. Mostra também que é um recurso da poesia amorosa, em que os tormentos da indiferença da mulher amada levam o poeta ao paroxismo - a colisão entre as ideias ou imagens evidencia o clima de absurdo e sem-razão em que ele mergulha. Mas não só nos poemas amorosos a impossibilia pode ocorrer: aparece em textos humorísticos e nas sátiras. De origem antiga, o adynaton teria surgido primeiramente com Arquíloco, no século VII a. C. A Idade Média teria se valido dessa figura graças principalmente a Virgílio. $O$ artifício persiste na Península Ibérica cultivado pelos quinhentistas petrarquizantes até os pré-românticos, passando pelos poetas barrocos (MOISÉS, 2004, p. 12-13).

Leiam-se alguns exemplos de adynaton no Cancioneiro Geral - que aparecem de forma satírica ou não:

Tornar-se de morte à vida / terá certo quem a vir, / e quanto mais a servir / terá pena mais crecida. (CGGR, 574, III) [Além do adynaton, o poeta usa a antítese clássica morte $x$ vida, num poema de cunho amoroso com certa veia satírica.]

O mundo é destruido, / ja nam ha i mal nem bem, / tudo se perde por quem / a mim leixa tam perdido. (CGGR, 576, III) [Também a temática é amorosa, mas não satírico.]

O mundo vai de maneira / que ja nele tudo achais: / ũu fez aguas na primeira, / outro foi casar à Beira, / este descobrio jamais / qu'at'aqui nam foi sabido, / qu'em braseiro se podia / fazer tal galantaria! (CGGR, 616, III) [O adynaton, nesse caso, 
é empregado em sentido satírico no poema em que um fidalgo "se alivia" de sua disfunção intestinal num braseiro.]

Vem-se tam pouco honrar / e prezar / neste tempo a gineta, / que j'agora vem andar / em muleta. / Este mal veo aqui / polas esporas, / qu'este trouxe nas más horas / pera si. (CGGR, 617, III)

Quem nesta vida cuidar / pode bem certo saber / qu'ee gram trabalho viver. / / Quem cuidar nesta mudança / qu'este triste mundo faz, / achará que nele jaz / a maior desconfiança. / E pois nunca dá bonança, / sem temor de se perder, / gram trabalho é viver. (CGGR, 795, IV)

O principio do cimento / assegura a fortaleza, / se o cume tem fraqueza / gerouse no fundamento. / É errada a qualidade / deste caso na primeira, / vem a tanta variedade, / que na fim e na metade / tem os pés por cabeceira. (CGGR, 803, IV) [O poeta inicia sua estrofe com um exemplum e, para marcar o desconcerto, recorre ao adynaton.]

...pois a agulha que levaes / vos faz ja do norte, sul. (CGGR, 803, IV)

Quintiliano comenta que os poetas, ao usarem do artifício embelezador das inversões, se valem da divisão dentro de uma mesma palavra como no caso tmese, como no exemplo que o próprio retor usa: Hyperboreo septem subiecta trioni, ${ }^{9}$ o que é completamente inadmissível na oratória. Em seguida, diz que, se a alteração não se faz no sentido, e somente produz uma variação da estrutura, prefere o retórico classificá-la como verbal figure (QUINTILIANO, VIII, VI, 66-67). Ernst Robert Curtius emprega o termo "versos rapportati" para denominar essa técnica, cuja expressão é já medieval; Curtius dá como exemplo clássico o epitáfio de Virgílio, em que "três sentenças, de quatro membros de construção gramatical idêntica, são dissolvidas e reconstruídas" (CURTIUS, 1996, p. 358-359). Os exemplos, muitos, de alteração de estrutura das frases e estrofes no Cancio-

9 “Os poetas chegam até a realizar o hipérbato mediante a ruptura das palavras: 'ao hiperbóreo Septentrião submetida', o que a prosa jamais admitiria. Mas isto, certamente, é o que permite que seja chamado com propriedade tropo, porque o sentido deve compor-se a partir de duas partes (MORA, 2000). 
neiro de Garcia de Resende. Denominados sínquise, creio ser melhor incluí-los como tropos, pois exige do leitor uma releitura da estrutura para se entender o sentido. Massaud Moisés, em seu Dicionário de termos literários, informa que é uma figura de construção "mediante a qual os termos de uma oração sofrem inversão ainda mais violenta que o hipérbato, de forma a configurar uma mixtura verborum, conforme atesta Quintiliano no Livro VIII $(2,14)$, ou o cais vocabular que torna obscuro o pensamento" (MOISÉS, 2004, p. 430). Nos exemplos abaixo, tirados do CGGR, entre colchetes, mostro uma possível leitura do pensamento obscuro do poeta, traduzindo, em alguns casos, palavras hoje desconhecidas:

Por vuestra contemplacion / ordenoo mi triste suerte / a mi terrible passion / pues vuestra conversacion / a mi coraçon es muerte. (CGGR, 140, I) [Por vuestra contemplacion, mi triste suerte ordenoo mi terrible passion, pues vuestra conversacion es muerte a mi coraçon.]

Quando responso cantar / ouvirdes, em voz erguida, / temeroso, / entam vos deve lembrar / como parto desta vida / saudoso! (CGGR, 216, II) [Quando ouvirdes cantar responso, em voz seguida, entam vos deve lembrar, temeroso, como parto saudoso desta vida!]

Eu em parte hei dele doo, / doutra folgo de morrer / polos matar. (CGGR, 216, II). [Em parte, eu hei doo dele, doutra, folgo de morrer polos matar.]

Nem me culpem se o mato, / e os outros qu'isto virem, / se me querem, / pois todolos azos cato, / pera m'eles nam servirem, / desesperem. (CGGR, 216, II) [Nem me culpem se o mato, se me querem, e os outros, qu'isso virem, desesperem, pois todolos azos cato, pera eles nam me servirem.]

Antre moros y judios / esta gram virtud se cante, / entre todos tres gentios / cantaram los metros mios / vuestra perfecion delante. (CGGR, 256, II) [Esta gram virtud se cante antre moros y judios, (entre eles?) tres gentios cantarão los versos mios delante vuestra perfecion.]

Por m'apartar da fee em que vivo, muitas vezes fui tentado deste diabo e de todas minha firmeza pôde mais que sua sabedoria, porque tam verdadeiro amor de tam 
falsas tentações nam podia ser vencido. (CGGR, 300, II) ["Todas" liga-se a "falsas tentações".]. [Este texto é o único em prosa no CGGR e antecede uma cantiga do Conde do Vimioso; ambos os textos - o em prosa e a cantiga - fazem parte de um "breve", "texto que era lido ou que se entregava à pessoa a quem era dirigido ou a quem presidia à representação dos momos e entremezes, e também às justas e torneios" (DIAS, 2003, p. 133-134, vol. VI).]

Dino de mui grande culpa / deve ser e reprendido / quem se nam vei destroido / e por vós nam é perdido; / eu lhe vejo maa desculpa. (CGGR, 573, III). [Quem nam se vei destroido deve ser reprendido, e por vós nam é perdido; eu lhe vejo maa desculpa (pois é) dino de mui grande culpa.]

Certo é que será seu / servidor desta senhora / quem nam for da que sam eu, / e esta tirando-a fora / todas leva à d'Abreu. (CGGR, 573, III) [Certo é que será servidor desta senhora quem nam for da que eu sam, e tirando fora esta, todas leva(m) à d'Abreu.]

Vive com dobrada dor / quem ser vosso nom alcanca, / e, depois que vosso for, / teraa muito boom senhor / e de si maa esperança. (CGGR, 580, III). [...teraa de si muito boom.. e maa esperança];

Sempre vivam suas famas, / destes jibões que fizestes, / com que tanto prazer destes / eestas damas. / Polo qual me dam cruzados, / mil presentes de lacõoes, / por lhe dar bem apodados / o vosso par de gibõoes, / do teor destes colhõoes / abrasiados. (CGGR, 590, III) [...prazer pelo qual, elas me dão cruzados, mil presentes de presuntos, porque o vosso par de gibões dá o motivo para bem motejar seus colhões feitos em brasa.]

Para os filósofos e retores antigos, é na elocutio que o orador deve centrar-se para convencer e comover seu auditório. Devem, então, valer-se de artifícios que embelezem seus discursos e, para isso, discriminam uma infinidade de recursos retóricos em que a palavra é de primordial importância. Da elocução oratória, na Idade Média em especial, serviram-se as artes poéticas - e obviamente os poetas - para, aliada à rima, à métrica e ao ritmo, ornamentar suas composições. 
Os estudos da Retórica não eram desconhecidos em Portugal, tendo sido promovidos por monarcas e encontrados nos mosteiros, os quais recorriam aos textos antigos para a divulgação do pensamento clássico, a partir do século XII, resplendendo no século XVI. A ciência do bem falar, segundo Quintiliano em seu Institutio oratória, serve-se das figuras - em que se alteram a forma e a linguagem - e dos tropos - em que a alteração destas se dá no nível denotativo e/ou conotativo da expressão, fazendo do discurso poético um locus da agudeza e da sutileza, quando, ainda de acordo com os retores e tratadistas antigos e medievais, usados com tenuidade e elegância.

Mas os recursos retóricos eram aludidos muito mais nas poéticas da Alta Idade Média e, nos séculos XIV-XVI, nos prólogos e proêmios de poetas castelhanos, que davam ao poeta as diretrizes do bem trovar - documento que faltou nas obras destes mesmos séculos em Portugal. Não por causa disso, desconheciam os poetas palacianos portugueses os artifícios retóricos, tanto que no Cancioneiro resendiano pôde-se recolher um farto elenco de figuras e tropos. Estes, aliados às Conquistas ultramarinas, com a mescla de várias línguas, trouxeram ao português a abertura para uma nova era, em todos os âmbitos da aventura humana.

Se se pensar nas figuras e tropos elencados nos poemas de formas mistas, pode-se afirmar que o Cancioneiro geral de Garcia de Resende não é apenas o repositório da tradição e da renovação, mas um rico arsenal do modo de compor do fim do século XV e início do XVI no Portugal dos Descobrimentos.

Neste curto estudo, a intenção era a de se analisar como, através dos artifícios retóricos, os poetas palacianos do Cancioneiro geral desenvolveram a elocutio - parte da Retórica que, na Idade Média, aliou-se à rima, ao metro e ao ritmo para, com as figuras e os tropos, enformar uma nova poética. Especificamente quanto ao cancioneiro de Resende, neste estudo delimitei a análise desses recursos aos poemas de formas mistas, uma vez que, acredito, neles concentra-se tudo o que representa a compilação, em termos de forma e de tema.

Deve-se acrescentar a este estudo o fato de que a diç̧ão está na ênfase aos tropos e às figuras e, focado em Quintiliano, o estudo destes resume muito do que os poetas medievais emularam, fazendo da Retórica mais do que uma ciência do bem falar - ela é uma virtude. Virtude que procuraram seguir com afinco os poetas palacianos do cancioneiro de Resende. 
Percebe-se nesses exemplos que a tradição - começada ao que parece na Antiguidade latina - veio se transformando pela leitura distinta que cada poeta criativo fez. Nessas peças, não há dúvida, além da releitura, prima o artista inventivo por dar sua contribuição individual.

Seriam apenas artifício poético ou expressão de um mundo invertido, transgredindo todo um conceito de estabilidade e de segurança?

\section{Referências}

ARISTÓTELES. Poetics. A translation and commentary for students of Litterature. Trad. Leon Golden. Comentários por O. B. Hardison, Jr. Tallahasee: Florida State University Press, 1981.

BAKHTIN, Mikhail. A cultura popular na Idade Média e no Renascimento: o contexto de François Rabelais. 4 ed. Trad. Yara Frateschi. São Paulo/Brasília: Hucitec/Edunb, 1999. CANCIONEIRO Geral de Garcia de Resende. Fixação do texto e estudo por Aida Fernanda Dias. Maia: Imprensa Nacional - Casa da Moeda, 1990-1993. Volumes I a IV.

CURTIUS, Ernst Robert. Literatura europeia e Idade Média latina. São Paulo: Hucitec, 1996.

DIAS, Aida Fernanda. Dicionário [comum, onomástico e toponímico]. Maia: Imprensa Nacional - Casa da Moeda, 2003.

FARAL, Edmond. Les Arts poétiques du XIle et du XIIIe siècle: recherches et documents sur la technique littéraire du Moyen Âge. Paris: Skalatine/Champion, 1982.

GRACIÁN, Baltasar. Agudeza y arte de ingenio. In CALDERÓN, Evaristo C. (ed.). Madri: Clásicos Castalia, 1988.

LAUSBERG, Heinrich. Elementos de retórica literária. Trad. R. M. Rosado Fernandes. Lisboa: Fundação Calouste Gulbenkian, 1966.

MOISÉS, Massaud. Dicionário de termos literários. São Paulo: Cultrix, 2004.

MORA, Carlos de Miguel. Serpens torquens: um tipo especial de hipérbato em latim. Ágora. Estudos Clássicos em Debate, 2, p. 101-120, 2000.

QUINTILIANO. Institutio oratoria. Livros VIII e IX. Trad. H. E. Butler. Ed. Bill Thyer. Disponível em:

http://penelope.uchicago.edu/Thayer/E/Roman/Texts/Quintilian/Institutio_Oratotia/ home.html. Acesso em 15 dez. 2016.

TAVANI, Giuseppe. O cômico e o carnavalesco nas cantigas de escarnho e maldizer. Boletim de Filologia, Lisboa, v. 29, n. 1-4, 1984. 